\title{
Co-activation of the amygdala, hippocampus and inferior frontal gyrus during autobiographical memory retrieval
}

\author{
Daniel L. Greenberg ${ }^{\mathrm{a}}$, Heather J. Rice ${ }^{\mathrm{a}, \mathrm{b}}$, Julie J. Cooper ${ }^{\mathrm{b}}$, Roberto Cabeza ${ }^{\mathrm{a}, \mathrm{b}}$, \\ David C. Rubin ${ }^{a}$, Kevin S. LaBar ${ }^{a}, b, *$ \\ a Psychological and Brain Sciences, Duke University, Durham, NC, USA \\ ${ }^{\mathrm{b}}$ Center for Cognitive Neuroscience, Duke University, P.O. Box 90999, Durham, NC 27708-0999, USA
}

Received 31 October 2003; received in revised form 17 August 2004; accepted 9 September 2004

\begin{abstract}
Functional MRI was used to investigate the role of medial temporal lobe and inferior frontal lobe regions in autobiographical recall. Prior to scanning, participants generated cue words for 50 autobiographical memories and rated their phenomenological properties using our autobiographical memory questionnaire (AMQ). During scanning, the cue words were presented and participants pressed a button when they retrieved the associated memory. The autobiographical retrieval task was interleaved in an event-related design with a semantic retrieval task (category generation). Region-of-interest analyses showed greater activation of the amygdala, hippocampus, and right inferior frontal gyrus during autobiographical retrieval relative to semantic retrieval. In addition, the left inferior frontal gyrus showed a more prolonged duration of activation in the semantic retrieval condition. A targeted correlational analysis revealed pronounced functional connectivity among the amygdala, hippocampus, and right inferior frontal gyrus during autobiographical retrieval but not during semantic retrieval. These results support theories of autobiographical memory that hypothesize co-activation of frontotemporal areas during recollection of episodes from the personal past.
\end{abstract}

(C) 2004 Elsevier Ltd. All rights reserved.

Keywords: Declarative memory; Emotion; Autonoetic consciousness; Neuroimaging; Prefrontal cortex

\section{Introduction}

Autobiographical memory consists of memories for personal life events. According to behavioral research (Rubin, Schrauf, \& Greenberg, 2003), neuropsychological case reports (e.g. Crovitz, 1986; Maguire, Vargha-Khadem, \& Mishkin, 2001b; O'Connor, Butters, Miliotis et al., 1992), and philosophical accounts (Brewer, 1995), autobiographical memory involves something more than the encoding, storage, and retrieval of data; namely, such memories are recollected (Brewer, 1995) or retrieved with a sense of reliving (Rubin, 1998). As with episodic memory, the person remembering the memory must be conscious of the prior conscious experience-a self-reflective mental state that Tulving terms autonoetic consciousness (Tulving, 1985).

\footnotetext{
* Corresponding author. Tel.: +1 919681 0664; fax: +1 9196810815.

E-mail address: klabar@duke.edu (K.S. LaBar).
}

Substantial neuropsychological research indicates that autobiographical memory depends upon medial temporal and prefrontal regions. Patients with medial temporal damage lose the ability to store new memories and may lose old memories (McClelland, McNaughton, \& O'Reilly, 1995; Scoville \& Milner, 1957; Squire, 1992), though the nature and extent of retrograde memory loss remains a matter of dispute (Knowlton \& Fanselow, 1998; Nadel \& Moscovitch, 1997, 1998). Damage to the ventral frontal lobes can result in confabulation, which involves memories that are disorganized, implausible and inaccurate (Baddeley \& Wilson, 1986; Moscovitch, 1989; Moscovitch \& Melo, 1997; Schacter, Norman, \& Koutstaal, 1998; Talland, 1965). Moreover, when right inferior frontal damage is combined with right anterior temporal damage (Calabrese et al., 1996; Kroll, Markowitsch, Knight, \& von Cramon, 1997) or is limited to the right uncinate fasciculus connecting these regions (Levine et al., 1998), retrograde amnesia can result. Given these findings, Markowitsch (1995) has proposed that the retrieval of old 
memories depends on the connections between anteromedial temporal and inferior frontal lobe structures, particularly those connections that course through the frontotemporal junction in the right hemisphere.

Despite a strong cognitive and neuropsychological tradition of autobiographical memory research, few neuroimaging studies have been conducted in this domain of memory. In a review of 11 studies, Maguire (2001) cited several issues that make autobiographical studies difficult to investigate with neuroimaging techniques. These include choice of appropriate control tasks as well as time course and verification of memory retrieval. Some neuroimaging studies have allowed only a relatively short time to retrieve memories, such as $4.3 \mathrm{~s}$ (Piefke et al., 2003) or $4.8 \mathrm{~s}$ (Conway et al., 1999). Behavioral experiments, however, have shown that autobiographical memories are retrieved piecemeal, not as single units, and that it may take as long as $10 \mathrm{~s}$ to retrieve the full memory (Rubin \& Schulkind, 1997). Studies that involved shorter trial durations may emphasize retrieval initiation and search processes rather than processes related to actual recollection, or ecphory.

The most consistent activations associated with autobiographical retrieval include the ventral prefrontal cortex, medial and lateral temporal lobe, temporal pole, and retrosplenial/cingulate regions (Maguire, 2001). However, the laterality of these activations has varied widely across studies (e.g. right-lateralization: Fink et al., 1996; Markowitsch et al., 2000; left-lateralization: Conway et al., 1999; Maguire \& Mummery, 1999; Maguire, Mummery, \& Büchel, 2000; Piefke, Weiss, Zilles, Markowitsch, \& Fink, 2003; bilateral; Andreasen, O'Leary, Cizadlo, Arndt \& Rezai, 1995; Conway et al., 2001, 2003; Maguire \& Frith, 2003). These studies have used a wide variety of control tasks, ranging from syllable counting (Maguire \& Mummery, 1999) to retrieval of fictitious memories (Markowitsch et al., 2000), which makes direct comparisons difficult. The majority of the studies also used blocked-design protocols, which raise additional issues regarding cognitive set and strategic processes that influence brain activation and laterality (e.g. Velanova et al., 2003; Wagner, Desmond, Glover, \& Gabrieli, 1998).

One factor that distinguishes autobiographical retrieval from other typical episodic memory tasks is the level of emotional arousal associated with the event (Bluck \& Li, 2001; Reisberg, Heuer, MacLean, \& O'Shaughnessy, 1988; Talarico, LaBar, \& Rubin, in press). There is strong evidence for a role of the amygdala in arousal-mediated memory effects (reviewed in Cahill \& McGaugh, 1998), and the amygdala is anatomically interconnected with the other frontotemporal components implicated in autobiographical memory as described above (Amaral, Price, Pitkänen, \& Carmichael, 1992). However, only a few studies have reported amygdala activation during autobiographical retrieval (including Fink et al., 1996; Maguire \& Frith, 2003; Markowitsch et al., 2000), even when emotional factors were systematically probed (Damasio et al., 2000; Piefke et al., 2003). With few exceptions (Maguire \& Frith, 2003), these studies used blocked designs, and successful retrieval was not verified in the scanner (although Piefke et al., 2003; Maguire \& Frith, 2003, did verify recollection retrospectively). Methodological issues, including MRI-related susceptibility artifact (LaBar, Gitelman, Mesulam, \& Parrish, 2001) and habituation across blocks of trials (Breiter et al., 1996; Taylor et al., 1998) may partially obscure activity in this brain region.

We conducted an fMRI study to address these issues and to specifically test for correlated activity among the amygdala, hippocampus and inferior frontal gyrus (IFG) during autobiographical retrieval. We aimed to fulfill several objectives in order to build upon previous work. First, an event-related design was implemented to avoid cognitive and brain activation issues associated with trial blocking. This design also enables the discarding of individual trials associated with retrieval failure. Second, a semantic retrieval control task was used to address the specificity of the results to the autobiographical domain. Semantic retrieval was used as a control task in several functional neuroimaging studies of autobiographical memory (Maguire, 2001; Ryan et al., 2001). We chose a prototypical semantic memory task (category exemplar generation) that, like autobiographical memory, involves multiple search and retrieval steps over an extended period of time. Third, we characterized the phenomenological properties of the autobiographical memories using our autobiographical memory questionnaire (AMQ) to verify that the types of memories elicited were similar to those obtained in our previous behavioral studies. Fourth, longer trial lengths were used to allow participants ample time to retrieve memories. The time to retrieve was also shortened by using a precue generation procedure (e.g. Maguire \& Mummery, 1999) in which participants recorded personalized cue words that were subsequently presented in the scanner to retrieve an associated autobiographical event. This aspect of the design helps minimize potential confounding effects related to different stages of retrieval emphasized across the episodic and semantic tasks (e.g. retrieval search versus ecphory). Finally, we conducted a targeted correlation analysis on activation in the amygdala, hippocampus, and IFG to investigate functional connectivity among these frontotemporal regions as a function of type of memory engaged.

Three predictions were made regarding the role of these frontotemporal regions in memory retrieval. First, we predicted greater activity in the amygdala, hippocampus, and right IFG during autobiographical retrieval relative to semantic retrieval. Second, we predicted greater correlated activity among these three regions in the autobiographical condition than in the semantic condition. These two hypotheses were derived from existing theories that posit specific interactions between the IFG and anteromedial temporal lobe regions in autobiographical recall (Markowitsch, 1995; Maguire, 2001). Third, we predicted greater activation in the left IFG during semantic retrieval relative to autobiographical retrieval, based on previous functional neuroimaging studies of semantic memory (for reviews, see Cabeza \& Nyberg, 2000; Thompson-Schill, 2003). 


\section{Methods}

\subsection{Participants}

Sixteen healthy adults participated in the study. Five of these participants were excluded due to excessive head movement during scanning (defined as a center-of-mass movement greater than $3.75 \mathrm{~mm}$ in any plane). The remaining 11 participants ( 5 male, 6 female; age range $=18-25$ ) were used in all analyses. All participants were right-handed and were negative for histories of psychiatric illness, neurological disorder, and drug abuse. The Institutional Review Board at Duke University Medical Center approved the protocol for use in human participants, and all participants gave informed consent prior to participation.

\subsection{Study design}

Participants were asked to think of 50 autobiographical memories and to fill out our autobiographical memory questionnaire (AMQ) (Rubin et al., 2003; Talarico et al., in press) for each memory. They were allowed to take the questionnaires home to fill them out at their leisure over several weeks, and were asked to return the completed questionnaire within $24 \mathrm{~h}$ of the first scanning session. Participants were informed that these memories could come from any point in their lives and did not have to be complete or totally coherent; that is, any autobiographical memory would suffice. The questionnaires asked them to provide a few keywords for each memory that would allow them to recall it while in the scanner. They were permitted to select any keywords they desired, except that they were asked to replace names with initials and to refrain from using taboo words that mention illicit activity. This latter instruction served to protect the identity of individuals not involved in the study and minimized the emotional impact of the cues themselves. They were also asked to rate the properties of each memory on a series of scales. The full questions and their rating scales are presented in the Appendix, along with the variable names to which we refer throughout the paper. The questions investigated recollection and belief, the component processes of the memory, and some of the reported properties of the events.

Participants were scanned in two separate sessions. They had 3-5 weeks to work on the questionnaire; most participants completed and returned it $24-72 \mathrm{~h}$ before the initial scan. Each scanning session was divided into five runs. Within each run, participants were presented with 10 of their autobiographical memory keywords and 10 category names from the Battig and Montague (1969) norms. All stimuli were presented for $24 \mathrm{~s}$ and followed by a fixation cross for $9 \mathrm{~s}$. Stimuli were presented using CIGAL, an in-house software program (Voyvodic, 1999). Category cues were displayed entirely in uppercase letters, whereas memory cues were entirely in lowercase letters. Within each run, stimuli were presented in a pseudorandom order subject to the constraint that no more than two trials of the same task were presented in a row. Total scan time for each session, including acquisition of anatomical scans, was approximately $1 \mathrm{~h}$ and $20 \mathrm{~min}$.

Participants were given three instructions: (1) when an autobiographical cue phrase appeared on the screen, they should think of the memory associated with that cue. When they recalled the associated memory, they should push a button on a response box and try to re-experience and maintain the memory in mind until the end of the trial; (2) when a category cue phrase appeared on the screen, they should think of as many exemplars of that category as possible and push a button when they could not think of any additional examples; (3) when a fixation cross appeared on the screen, they should look at it without making any response. In both case 1 and case 2, the trial length was $24 \mathrm{~s}$; if they did not make a response within this time, the keywords disappeared and were replaced with the fixation cross. Two to three weeks after the first scan, participants returned for a second scan. The parameters and experimental design were identical, except that the runs were presented in reverse order; the same autobiographical and semantic keywords were used on both occasions. This second scanning session was run to increase statistical power. Data were collapsed across scanning sessions for each participant for the region-of-interest analysis (see Section 2).

\subsection{Questionnaire}

\subsubsection{Recollection and belief}

Philosophers and psychologists have identified recollection or autonoetic consciousness as a fundamental property of autobiographical memory (Baddeley, 1992; Brewer, 1986, 1995; Greenberg \& Rubin, 2003; Rubin, 1998; Rubin \& Greenberg, 1998, 2003; Tulving, 1983, 1985; Wheeler, Stuss, \& Tulving, 1997). We formulated three rating scales intended to assess the sense of reliving. The first question asked whether the subjects felt as though they were reliving the original event. The second question was taken specifically from work by Tulving and his colleagues (e.g. Wheeler et al., 1997), and asked whether the memory came with a sense of mentally traveling back in time to the original experience. The third question asked whether the subjects could remember the event, or if they simply knew it had happened (remember/know). We included reports of belief along with reports of reliving by asking our subjects to judge whether the event really occurred in the way it was remembered, or whether some parts of the memory had been imagined (our real/imagine variable). Also, given the research on field/observer perspectives (e.g. Nigro \& Neisser, 1983), we asked whether participants saw the memory through their own eyes or through the eyes of an outside observer.

\subsubsection{Component processes}

The most important of the component processes involved in having and reporting an autobiographical memory in the psychological and philosophical literatures is visual imagery (Brewer, 1995; Greenberg \& Rubin, 2003; Larsen, 1998; Rubin, 1998; Rubin \& Greenberg, 1998, 2003). Visual im- 
agery can be divided on behavioral and neural grounds into two systems: object or descriptive imagery and spatial imagery. More colloquially, these comprise a "what" and a "where" system (Rubin, 1995; Ungerleider \& Mishkin, 1982). We measured the descriptive component of visual imagery by using a rating scale that asks whether the event could be seen in the mind (our see variable). We examined the spatial component by asking whether the setting and the spatial layout could be recalled.

We asked whether the memory could be heard in the mind (hear) to contrast visual imagery from imagery in general and because of the interest in auditory imagery (Reisberg, 1992). Autobiographical memories often contain reports of language, and language is the most common way to communicate autobiographical memories. We therefore asked whether people were talking in the memory (talk) and whether the memory comes in words. Because of the important role that narrative plays in autobiographical memory (see Rubin, 1995, 1998, for reviews) and because narrative can be viewed as independent of language (Greenberg \& Rubin, 2003; Rubin \& Greenberg, 2003), we asked three questions about narrative coherence: whether the memory came as a coherent story or as isolated facts or observations; whether it was complete, or fragmented with missing pieces; and whether it had personal coherence and fit into the person's life story.

In addition to the more traditionally cognitive properties we have just described, it is clear that emotions play an important and actively researched role in autobiographical memory (Christianson, 1992; Christianson \& Safer, 1995). We asked whether the emotions of the event were reinstated, and what their valence was.

\subsubsection{Reported properties of events}

Because rehearsal, especially spaced rehearsal (Bahrick, 1979; Rubin, 1995), improves retention, because the report of such rehearsal varies for different types of cues (Rubin, Groth, \& Goldsmith, 1984), and because in many models rehearsal can lead to the development of a schema or to the transfer from episodic to semantic memory (Tulving, 1972), we asked subjects to estimate the number of times they had previously thought about the memory. We also asked whether the memory consisted of general knowledge about the event, or whether it contained additional information.

Sometimes multiple occurrences of an event can lead to a single autobiographical memory, a phenomenon that is important to the study of autobiographical memory in depression and post-traumatic stress disorder (McNally, Litz, Prassas, Shin, \& Weathers, 1994; Williams, 1995), as well as autobiographical memory in general (Conway \& PleydellPearce, 2000). To capture this distinction, we asked participants to judge whether the memory was for an event that occurred once within a single day (once/many) and, if not, whether it was a summary or merging of similar events, or whether it was for an event that extended for a period greater than 1 day (merged/extended). The 1-day duration followed directly from Williams's work. Finally, because of the inter- est in the distribution of memories over the lifespan (Crovitz \& Schiffman, 1974; Rubin \& Schulkind, 1997; Schrauf \& Rubin, 1998) and because older memories might be less intense on all scales due to forgetting, we asked subjects to date their memories so we could calculate the age of memory.

\subsubsection{Scanning parameters}

MR images were acquired with a $1.5 \mathrm{~T}$ General Electric Signa Nvi scanner (Milwaukee, WI) equipped with $41 \mathrm{mT} / \mathrm{m}$ gradients. The participant's head was immobilized using a vacuum cushion and tape. The anterior commissure (AC) and posterior commissure (PC) were identified in the mid-sagittal slice of a localizer series. Thirty-four contiguous slices were prescribed parallel to the AC-PC plane for high-resolution T1-weighted structural images (repetition time $(\mathrm{TR})=450 \mathrm{~ms}$, echo time $(\mathrm{TE})=20 \mathrm{~ms}$, field-of-view $(\mathrm{FOV})=24 \mathrm{~cm}$, matrix $=256^{2}$, slice thickness $=3.75 \mathrm{~mm}$ ). An additional series of T1-weighted structural images oriented perpendicular to the AC-PC were acquired using the same parameters. Gradient echo echoplanar images sensitive to blood-oxygen-level-dependent (BOLD) contrast were subsequently collected in the same transaxial plane as the T1-weighted structural images $(\mathrm{TR}=3 \mathrm{~s}, \mathrm{TE}=40 \mathrm{~ms}$, FOV $=24 \mathrm{~cm}$, matrix $=64^{2}$, flip angle $=90^{\circ}$, slice thickness $=3.75 \mathrm{~mm}$, thereby producing $3.75 \mathrm{~mm}^{3}$ isotropic voxels).

\subsubsection{FMRI data analysis}

A priori anatomical regions of interest (ROIs) were drawn on each subjects' high-resolution coronal anatomic image. ROIs were drawn on a slice-by-slice basis using an inhouse computer program (Brain Imaging and Analysis Center, Duke University Medical Center) within the Matlab environment (Mathworks Inc., Natick, MA) on a PC-DOS platform. Mean signal change for each voxel within each ROI was extracted for the first five post-stimulus time points relative to the $6 \mathrm{~s}$ pre-stimulus baseline. These data were then plotted to characterize the hemodynamic response time course for each condition. No smoothing, normalization or thresholding was employed in the ROI analysis. The time courses for the ROIs were also examined by hemisphere and anterior-posterior slice distribution. Rostrocaudal profile of activation was considered in the analysis because previous neuroimaging studies have shown anterior-posterior gradients in emotionand memory-related activity in the medial temporal and inferior prefrontal regions of interest (e.g. Breiter et al., 1996; Lepage, Habib, \& Tulving, 1998; Schacter \& Wagner, 1999; Strange, Fletcher, Henson, Friston, \& Dolan, 1999; Wagner et al., 2001; Yamasaki, LaBar, \& McCarthy, 2002). Statistical analyses were performed on these data by comparing percent signal change at experimentally-derived peak time points for each ROI using repeated-measures ANOVA followed by post-hoc pairwise dependent $t$-tests. An $\alpha$ level of 0.05 was used to determine significance in these analyses.

In addition, a correlational analysis was conducted using the ROI data extracted from individual participants. This 
analysis used peak activity to determine the correlation of activity across region, hemisphere and anterior/posterior division for the two retrieval conditions. Pearson correlation coefficients were calculated for each ROI crossed with all other regions, separated by subdivision and hemisphere, except that within each hemisphere, correlations within a particular region were not considered. A reduced $\alpha$ level of 0.01 was used to determine significance for all correlations, given the multiple comparisons constituting the analysis. Note that this analysis does not compute correlations based on groupaveraged data sets.

The ROIs included the amygdala, hippocampus and IFG. Anatomical definition of each region was guided by the anatomical borders described in Talairach and Tournoux (1988), Duvernoy (1999) and Convit et al. (1999). More specifically, the boundaries of each ROI were as follows.

\subsubsection{Amygdala}

The anterior border was defined at the point where the optic chiasm first became discontinuous. The ovoid shape of the amygdala was followed from the ventrolateral white matter tract to the dorsomedial cerebral spinal fluid (CSF) boundary. Tracing continued posteriorly through the point where the angular bundle projects out to create the inferomedial boundary. Posterior to this section, the hippocampus cuts in ventrally at the level of the temporal horn, and the white matter tract at the amygdalo-hippocampal junction was used as the ventral limit. The amygdala appeared on four slices, which were divided into anterior (two slices) and posterior (two slices) subdivisions.

\subsubsection{Hippocampus}

The anterior border was defined as the slice on which the inferior lateral ventricles appeared roughly horizontal without any body of gray matter visible below them. Tracing followed along the gray-white matter border along the inferior side of the hippocampus, proceeded across the border of the inferior lateral ventricle, transected the amygdalo-hippocampal junction along the body of the hippocampus, and transected the entorhinal cortex and parahippocampal gyrus at approximately their most medial points. On posterior slices, tracing followed a similar procedure; the main difference was that the fimbria was transected when visible. The posterior border was defined as the first slice on which the crus of the fornix was visible through the pulvinar of the thalamus. The hippocampus appeared on seven slices, which were divided into anterior (three slices) and posterior (four slices) subdivisions.

\subsubsection{Inferior frontal gyrus (IFG)}

The IFG is bordered superiorly by the inferior frontal sulcus and laterally by CSF. Tracing began in the anteriormost slice where white matter could be discerned between the lateral orbital sulcus and the middle frontal gyrus. In anterior sections, the inferior border was the horizontal ramus of the lateral fissure, whereas in posterior sections, the inferior bor- der was the circular insular sulcus. The medial border was defined by connecting the ends of the superior and inferior borders across the white matter. Drawing ended posteriorly on the slice before the IFG was obstructed by the precentral gyrus at the central sulcus. A formal distinction was not made among the pars orbitalis, pars triangularis, and pars opercularis. The IFG appeared on six slices, which were divided into anterior (three slices) and posterior (three slices) subdivisions.

Finally, to identify activity in brain regions that were not our a priori focus, we conducted a whole-brain voxel-based analysis using SPM99 (Wellcome Department of Neurology, London, UK). The functional images were corrected for their interleaved acquisition order and realigned to the first image to correct for head motion. The realigned images were then co-registered to the co-planar anatomical image for each participant. The co-planar anatomical images were spatially normalized to a common stereotactic space using the Montreal Neurological Institute template included in SPM99. The functional images were then normalized to the common space using the parameters defined by the co-planar anatomical image and smoothed using an $8 \mathrm{~mm}$ isotropic Gaussian kernel. Hemodynamic responses to the memory retrieval cues were isolated by convolving a vector of onset times of the cues with a synthetic hemodynamic response function and its temporal derivative. The general linear model was used to model the effects of interest and other confounding effects, such as session effects or motion-related artifacts, for each participant. Across participant comparisons were made with a random effects model in which linear contrasts were first applied to the parameter estimates of interest, resulting in a $t$-statistic for every voxel. Then, group averages were calculated by employing pairwise $t$-tests on the resulting contrast images. Statistical parametric maps were thresholded at the level of $p<0.01$ uncorrected for our a priori regions of interest (amygdala, hippocampus, and inferior frontal gyrus), and $p<0.001$ uncorrected for all other brain regions. A spatial extent threshold of three contiguous voxels was used for all brain regions.

\section{Results}

\subsection{Behavioral results}

Participants took an average of $3.28 \mathrm{~s}($ S.D. $=1.57 \mathrm{~s}$ ) to retrieve an autobiographical memory and $14.50 \mathrm{~s}($ S.D. $=2.57 \mathrm{~s}$ ) to finish generating category exemplars. On average, participants successfully retrieved memories on $98.7 \%$ of the trials and finished generating category exemplars on $81.4 \%$ of trials. Trials in which participants failed to retrieve an autobiographical memory were dropped. No semantic memory trials were dropped because the failure to finish generating exemplars meant that the process of retrieval had continued throughout the trial. As in other studies (Maguire \& Frith, 2003), participants reported retrieving the memory of the original experience, not the questionnaire or the previous scanning session. Table 1 presents means and standard 
Table 1

Behavioral ratings of the phenomenological properties of the memories from the autobiographical memory questionnaire

\begin{tabular}{lrr}
\hline Variable & Mean & S.D. \\
\hline Reliving & 4.2 & 1.7 \\
Hear & 3.9 & 1.7 \\
See & 5.2 & 1.2 \\
Talk & 4.1 & 1.8 \\
Spatial & 4.8 & 1.5 \\
Emotions & 4.4 & 1.9 \\
Setting & 5.4 & 1.4 \\
Remember/know & 5.9 & 1.2 \\
In words & 2.6 & 1.8 \\
Back in time & 4.5 & 1.6 \\
Story & 4.6 & 1.8 \\
Fragmented & 3.8 & 2.1 \\
General & 2.7 & 1.7 \\
Coherence & 4.7 & 1.8 \\
Valence & 5.0 & 1.9 \\
Field/observer & 1.2 & 0.5 \\
Real/imagine & 6.3 & 0.9 \\
Rehearsal & 4.0 & 1.6 \\
Once/many & 0.8 & 0.4 \\
Merged/extended & 0.6 & 0.5 \\
Age of memory (days) & 1750 & 1785 \\
\hline
\end{tabular}

deviations of the participants' ratings on the questionnaire. They are within 1 S.D. of results we obtained in an earlier behavioral study with 50 participants (Rubin et al., 2003).

\subsection{FMRI results: ROI analyses}

Results from the ROI analyses on the amygdala, hippocampus and IFG are presented in Fig. 1. For the amygdala, ANOVA revealed a significant three-way interaction among retrieval condition, hemisphere and slice, $F(3,30)=3.48$, $p<0.03$, a two-way interaction between hemisphere and slice, $F(3,30)=3.27, p<0.04$, and a main effect of hemisphere, $F(1,10)=5.64, p<0.04$. Follow-up dependent $t$-tests showed a left hemisphere bias in amygdala activation during autobiographical retrieval, which was especially prominent in anterior slices (Fig. 1a).

For the hippocampus, ANOVA revealed significant main effects of retrieval condition, $F(1,10)=10.30, p<0.009$, and hemisphere, $F(1,10)=6.78, p<0.03$. These results indicate greater hippocampal activation during autobiographical retrieval and a left hemisphere bias (Fig. 1b).

For the IFG, ANOVA revealed a significant three-way interaction among retrieval condition, hemisphere, and slice, $F(5,50)=2.58, p<0.04$, and a main effect of hemisphere, $F(1,10)=27.67, p<0.001$. Overall, there was greater activation in the left hemisphere; however, post-hoc dependent $t$-tests showed a posterior gradient of activation in the right hemisphere during autobiographical retrieval (Fig. 2). Inspection of the raw time courses of mean activity in the left IFG indicated a more protracted duration of activity during semantic retrieval, despite similar peak amplitudes of activity in both conditions (Fig. 1c). This qualitative impression was confirmed by a post-hoc ANOVA, which showed a signifi- cant interaction between retrieval condition and time from 9 to $15 \mathrm{~s}$ post-stimulus, $F(2,20)=21.59, p<0.001$.

\subsection{FMRI results: correlational analyses}

Correlational analyses revealed different patterns of co-activation among the amygdala, hippocampus and IFG across the two retrieval conditions (Fig. 3). During autobiographical retrieval, activation in left posterior hippocampus was significantly correlated with activation in right posterior IFG, $r(9)=0.83, p<0.002$ and left posterior amygdala, $r(9)=0.89, p<0.0002$. Activation in left posterior amygdala was also correlated with activation in right posterior IFG, $r(9)=0.76, p<0.007$, and right anterior IFG, $r(9)=0.72$, $p<0.012$. The fact that significant correlations involved posterior amygdalar and hippocampal regions whereas the overall level of activity was greater in anterior areas of these structures illustrates the fact that activation and correlational analyses can reveal different aspects of neural functioning. We also note that activity in the right IFG was also correlated with that in the right amygdala and right hippocampus at a less stringent $\alpha$ level of 0.05 , but no such correlations were found with the left IFG at this reduced threshold. During semantic retrieval, activation in left anterior hippocampus was correlated with activation in left anterior amygdala, $r(9)=0.76, p<0.007$, and the anterior IFG was correlated across hemispheres, $r(9)=0.77, p<0.006$, but there were no significant frontotemporal interactions.

\subsection{FMRI results: analysis of testing session effects}

In the ROI-based analyses described above, data were collapsed across testing sessions to increase statistical power. To evaluate whether the retrieval activations varied according to the testing session (Session 1 versus Session 2), four-way repeated-measures ANOVAs were conducted on each ROI separately using testing session, memory condition, hemisphere, and slice as within-subjects factors, with Greenhouse-Geisser corrections as appropriate. The results showed a significant main effect of testing session in all three ROIs: amygdala, $F(1,10)=21.65, p<0.0009$; hippocampus, $F(1,10)=5.38, p<0.04$; IFG, $F(1,10)=6.33, p<0.03$. In all three ROIs, overall signal intensity decreased across the two testing sessions. In addition, the IFG showed an interaction between hemisphere and testing session, such that the leftward asymmetry in activation was reduced across testing sessions, $F(1,10)=5.53, p<0.04$. Importantly, there were no significant main effects or interactions with memory condition (autobiographical/semantic). Thus, there was no differential impact of testing session on brain activation as a function of retrieval type.

\subsection{FMRI results: voxel-based analyses}

The SPM99 random-effects analysis conducted on the whole brain confirmed activation in our a priori regions of 

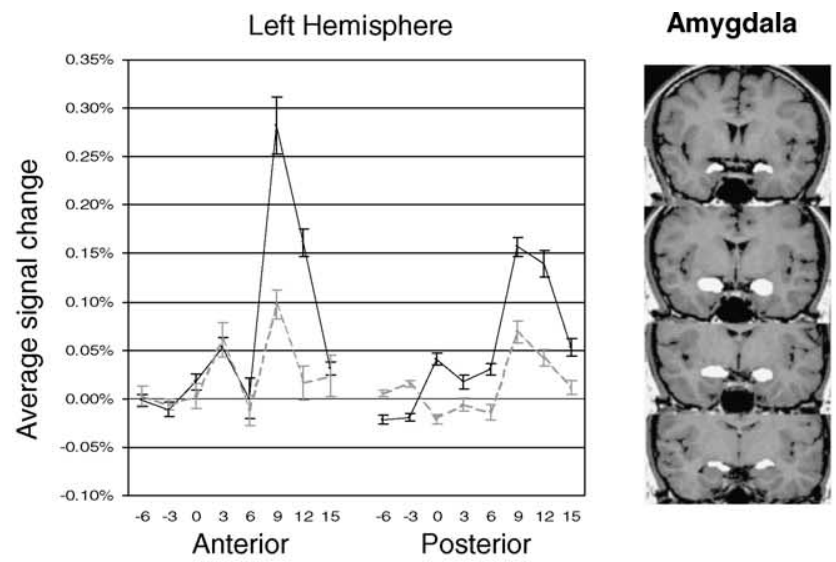

(a)

Time (sec)

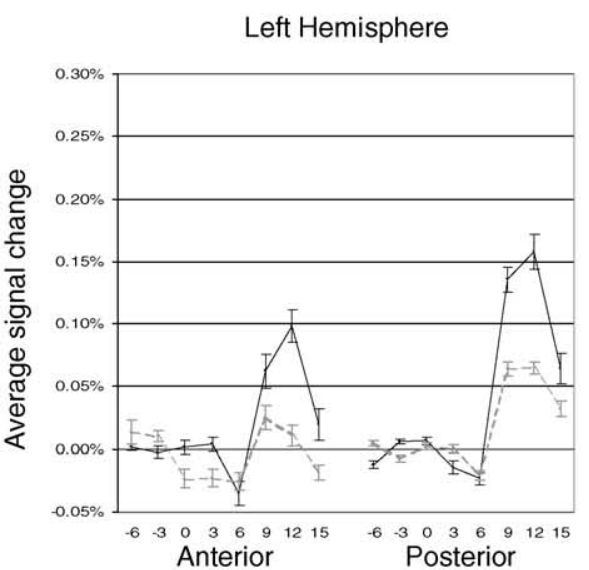

Hippocampus

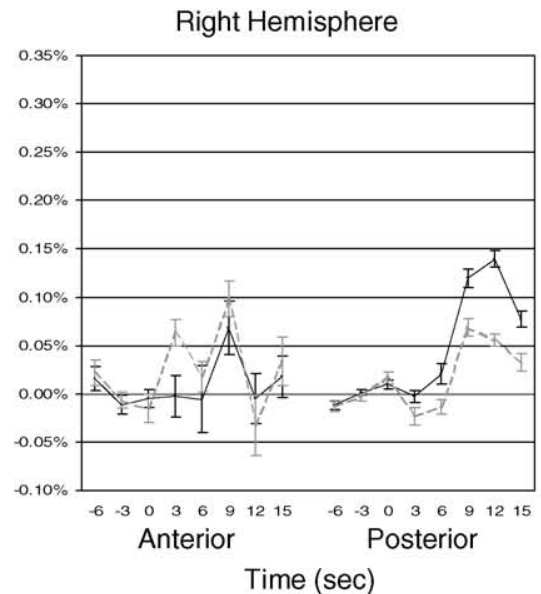

Right Hemisphere
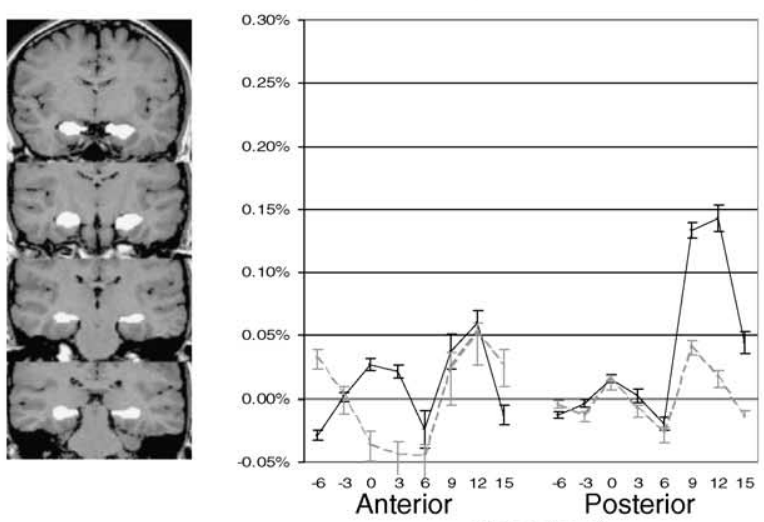

Time (sec)

(b)

Time (sec)

Left Hemisphere

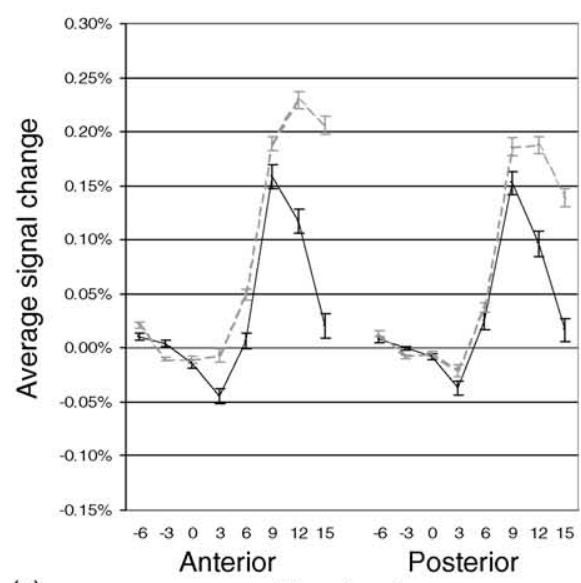

(c)
Inferior Frontal Gyrus

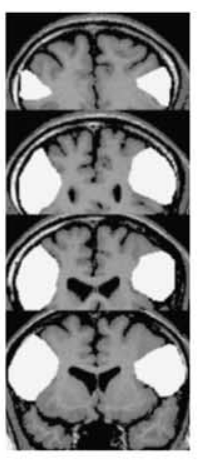

Right Hemisphere

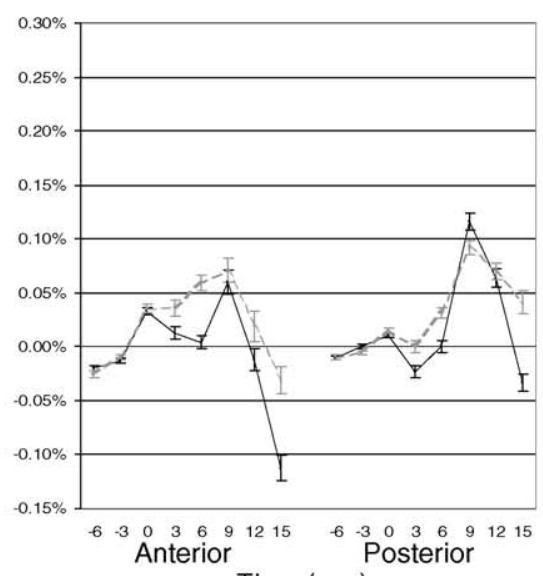

Time (sec) (IFG). Percent signal changes for the autobiographical and semantic retrieval conditions are expressed relative to pre-stimulus fixation baseline. The shaded areas indicate the locations of the ROIs and do not represent activation. For visualization purposes, data are collapsed into anterior and posterior subregions and averaged across the two scanning sessions. Middle panel shows four selected slices from an individual brain for each region of interest. Error bars represent S.E.M. AM: autobiographical memory; SM: semantic memory. 
Left IFG

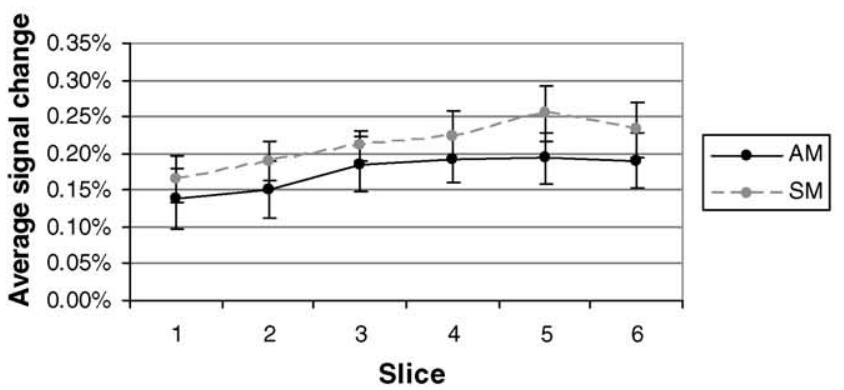

Right IFG

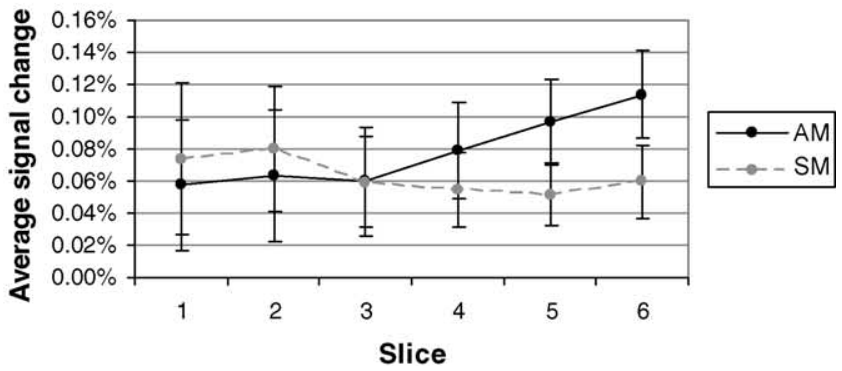

Fig. 2. Slice distribution of mean activity in the inferior frontal gyrus (IFG) at $9 \mathrm{~s}$ post-stimulus. Data are averaged across the two scanning sessions. Slice 1 is the most anterior slice, and slice 6 is the most posterior slice. Error bars represent S.E.M. AM: autobiographical memory; SM: semantic memory.

interest during autobiographical retrieval (Table 2). Other brain regions that were more engaged during autobiographical than semantic retrieval included the precuneus/posterior cingulate (Brodmann area (BA) 23/30/31), temporoparietal junction (BA 39), medial and lateral aspects of the temporal lobe (including fusiform (BA 37) and parahippocampal (BA 35) gyri, and middle (BA 21/39) and superior (BA 22) temporal gyri, respectively), caudate nucleus, frontal pole (BA 9/10), and middle (BA 6) and superior (BA 6) frontal gyri. Brain regions that were more engaged during semantic than autobiographical retrieval included the inferior parietal lobule (BA 40) and lateral orbitofrontal cortex (BA 11).

\section{Discussion}

The present study investigated the contribution of medial temporal and inferior frontal regions to autobiographical memory retrieval. A cued recall task was implemented using personalized cue words created prior to scanning, which were interleaved in an event-related design with semantic cue words for a category generation task. In support of our first hypothesis, we found greater activation in the left amygdala, left hippocampus, and right IFG during autobiographical retrieval relative to semantic retrieval. This result extends previous neuroimaging and neuropsychological studies that highlight the involvement of frontotemporal structures in autobiographical memory (reviewed in Maguire, 2001). In support of our second hypothesis, correlational analysis showed a tighter coupling of activity across these three regions during autobiographical retrieval relative to semantic retrieval. This finding suggests a modulation of cohesiveness between ventral frontal and medial temporal lobe compartments as a function of the type of retrieval engaged. Finally, although the left IFG contributed to both autobiographical and semantic memory retrieval, semantic processing was associated with activ-
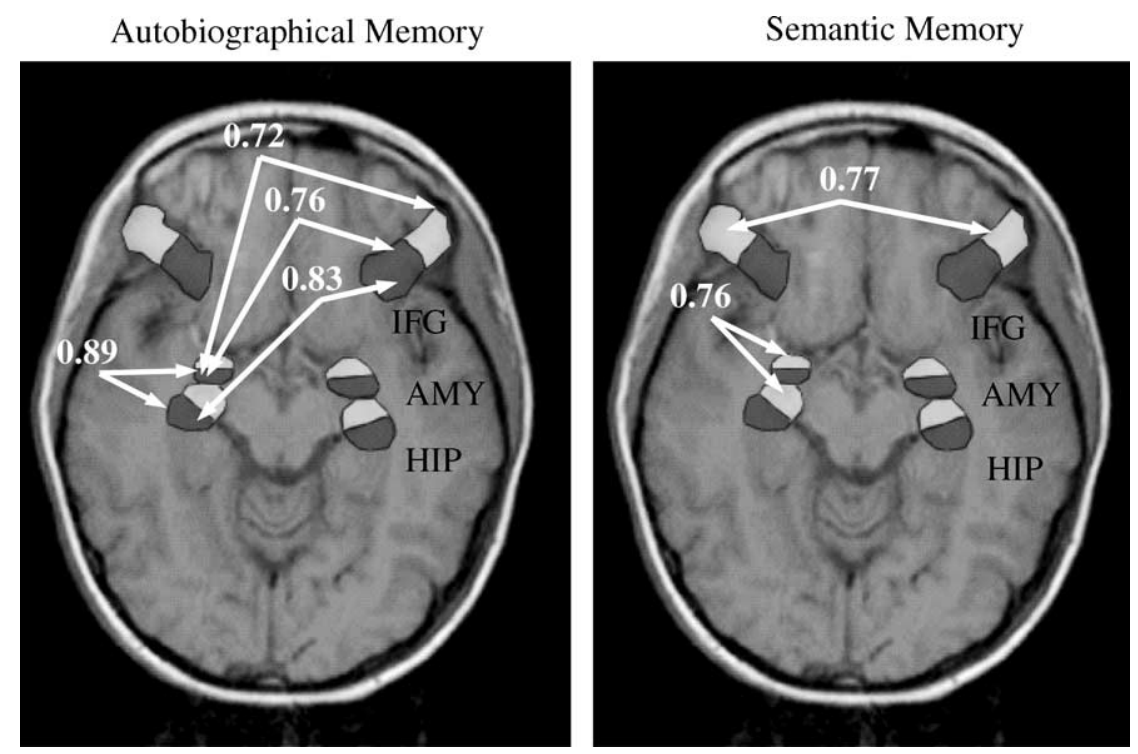

Fig. 3. Schematic illustration of results from the correlational analysis for each retrieval condition. Anterior subregions are indicated by light shading, and posterior subregions are indicated by dark shading. Shading grossly depicts subregion boundaries for visualization purposes only. Numeric values represent significant Pearson correlation coefficients $(p<0.01)$ between the two subregions connected by arrows. AMY: amygdala; HIP: hippocampus; IFG: inferior frontal gyrus. 
Table 2

Results from the voxel-based random-effects analysis using SPM99

\begin{tabular}{|c|c|c|c|c|c|c|}
\hline Region & $\mathrm{BA}$ & Side & $T$ value & $x$ & $y$ & $z$ \\
\hline \multicolumn{7}{|l|}{ Autobiographical > semantic } \\
\hline Precuneus/posterior cingulate & $31 / 23 / 30$ & $\begin{array}{l}\text { Left } \\
\text { Right }\end{array}$ & $\begin{array}{l}6.67 \\
4.71\end{array}$ & $\begin{array}{r}-8 \\
8\end{array}$ & $\begin{array}{l}-68 \\
-60\end{array}$ & $\begin{array}{l}15 \\
19\end{array}$ \\
\hline Superior frontal gyrus & 6 & Left & 6.29 & -8 & 15 & 64 \\
\hline Parahippocampal gyrus & 35 & Right & 6.01 & 23 & -30 & -19 \\
\hline Middle temporal gyrus & $\begin{array}{l}21 \\
39\end{array}$ & $\begin{array}{l}\text { Right } \\
\text { Right }\end{array}$ & $\begin{array}{l}5.77 \\
5.47\end{array}$ & $\begin{array}{l}56 \\
45\end{array}$ & $\begin{array}{l}-15 \\
-68\end{array}$ & $\begin{array}{r}-19 \\
15\end{array}$ \\
\hline Middle frontal gyrus & 6 & Left & 5.28 & -45 & 4 & 45 \\
\hline Superior temporal gyrus & 22 & $\begin{array}{l}\text { Left } \\
\text { Left }\end{array}$ & $\begin{array}{l}5.14 \\
4.86\end{array}$ & $\begin{array}{l}-49 \\
-45\end{array}$ & $\begin{array}{l}-60 \\
-53\end{array}$ & $\begin{array}{l}15 \\
19\end{array}$ \\
\hline $\begin{array}{l}\text { Inferior frontal gyrus } \\
\text { Caudate }\end{array}$ & 45 & $\begin{array}{l}\text { Right } \\
\text { Right }\end{array}$ & $\begin{array}{l}5.05 \\
4.82\end{array}$ & $\begin{array}{l}56 \\
19\end{array}$ & $\begin{array}{r}30 \\
-4\end{array}$ & $\begin{array}{r}4 \\
23\end{array}$ \\
\hline Hippocampus & & $\begin{array}{l}\text { Right } \\
\text { Left }\end{array}$ & $\begin{array}{l}4.61 \\
3.45\end{array}$ & $\begin{array}{r}26 \\
-28\end{array}$ & $\begin{array}{l}-15 \\
-20\end{array}$ & $\begin{array}{l}-19 \\
-17\end{array}$ \\
\hline $\begin{array}{l}\text { Frontal pole } \\
\text { Temporoparietal junction } \\
\text { Fusiform gyrus }\end{array}$ & $\begin{array}{r}9 / 10 \\
39 \\
37\end{array}$ & $\begin{array}{l}\text { Left } \\
\text { Left } \\
\text { Left }\end{array}$ & $\begin{array}{l}4.57 \\
4.43 \\
4.26\end{array}$ & $\begin{array}{l}-11 \\
-38 \\
-26\end{array}$ & $\begin{array}{r}53 \\
-83 \\
-45\end{array}$ & $\begin{array}{r}23 \\
23 \\
-19\end{array}$ \\
\hline Amygdala & & $\begin{array}{l}\text { Left } \\
\text { Right }\end{array}$ & $\begin{array}{l}2.91 \\
2.89\end{array}$ & $\begin{array}{r}-22 \\
25\end{array}$ & $\begin{array}{r}-6 \\
-10\end{array}$ & $\begin{array}{l}-21 \\
-21\end{array}$ \\
\hline \multicolumn{7}{|l|}{ Semantic $>$ autobiographical } \\
\hline $\begin{array}{l}\text { Inferior parietal lobe } \\
\text { Lateral orbitofrontal cortex }\end{array}$ & $\begin{array}{l}40 \\
11\end{array}$ & $\begin{array}{l}\text { Left } \\
\text { Right }\end{array}$ & $\begin{array}{l}5.52 \\
4.97\end{array}$ & $\begin{array}{r}-49 \\
30\end{array}$ & $\begin{array}{r}-49 \\
56\end{array}$ & $\begin{array}{r}45 \\
-11\end{array}$ \\
\hline
\end{tabular}

Spatial coordinates $(x, y, z)$ are in Montreal Neurologic Institute space. BA: Brodmann area.

ity that was more prolonged, in partial support of our third hypothesis, though this may be attributable to the temporallyextended nature of the task. Together, these results advance an understanding of the neural mechanisms subserving recall of personal episodic information and their distinction from mechanisms subserving semantic memory.

The behavioral results indicated that the phenomenological properties of the memories being probed in the scanner were similar to those obtained in independent behavioral studies (e.g. Rubin et al., 2003), thus validating our method for procuring autobiographical events in the fMRI environment. The pre-cueing procedure reduced the typical time course for autobiographical memory retrieval to within 1 TR of cue onset. This, combined with the fact that participants were engaged in the semantic task for the majority of the trial duration, minimized potential confounds across the two conditions related to differences in time-on-task or different aspects of retrieval emphasized (e.g. initiation/search versus ecphory). By employing an event-related design, we avoided the impact of trial blocking on hemispheric asymmetries associated with memory retrieval (Velanova et al., 2003; Wagner et al., 1998) and eliminated individual trials characterized by memory failure, which was verified on-line. Lastly, the ROI-based statistical approach allowed: (1) a more precise analysis of the contribution of adjacent medial temporal lobe structures to memory retrieval based on individual participants' anatomy; (2) assessment of the covariance of activity in these regions with that of the IFG; and (3) char- acterization of differences in IFG hemodynamic profiles as a function of retrieval condition. The implications of these results are further discussed for each brain region below.

\subsection{Role of the amygdala}

Much evidence supports a role for the amygdala in the encoding of positive and negative emotional memories (Dolcos, LaBar, \& Cabeza, 2004; Hamann, Elt, Grafton, \& Kilts, 1999 reviewed in Cahill \& McGaugh, 1998; Hamann, 2001). Only a few studies, however, have reported amygdala activation during retrieval (Fink et al., 1996; Dolan, Lane, Chua, \& Fletcher, 2000; Maguire \& Frith, 2003; Markowitsch et al., 2000; Rausch et al., 1996). Most of these studies have not examined the relation between amygdala activation and emotional intensity or valence; one study found no such relation (Maguire \& Frith, 2003). Autobiographical events tend to have relatively high emotional salience due to their personal involvement, and emotional content influences the phenomenological properties of the memory and their recall accessibility (Bluck \& Li, 2001; Talarico et al., in press). Autobiographical paradigms may thus be useful for assessing the role of the amygdala in memory retrieval. The behavioral results from the present study indicated that the autobiographical memories tended to be positive in valence and tended to evoke the same emotional intensity that was present during the original experience (Table 1). The peak activity of the amygdala's response was located in a more anterior re- 
gion of the left hemisphere, although the correlation with other brain regions was stronger in its more posterior aspect. This difference may reflect differential involvement of amygdaloid subnuclei, which are difficult to resolve at 1.5T. Although we observed amygdala activation in the present study, many previous studies have not reported amygdala responses (e.g. Conway et al., 1999, 2001, 2003; Maguire \& Mummery, 1999; Maguire et al., 2000; Piefke et al., 2003; Ryan et al., 2001), even when specific emotions were probed (Damasio et al., 2000; George, Ketter, Parekh, Herscovitch, \& Post, 1996; Lane et al., 1997; Liotti et al., 2000; Mayberg et al., 1999; Pardo, Pardo, \& Raichle, 1993). Moreover, there are few autobiographical memory studies in neurologic patients with amygdala damage (e.g. Mori et al., 1999).

Several factors contribute to the difficulty in eliciting amygdala activation during autobiographical retrieval. First, amygdala responses to emotional stimuli tend to habituate over time, especially in blocked-design experiments (e.g. Breiter et al., 1996; Taylor et al., 1998). Second, MRI-related susceptibility artifact in the vicinity of the amygdala varies across participants (LaBar et al., 2001). This issue may be particularly formidable to voxel-wise statistical procedures that require precise spatial overlap of activity across individuals to characterize group-averaged results. Such variability can be minimized by tailored pulse sequences that reduce susceptibility artifact in the medial temporal lobes (Posse et al., 2003; Wang, Song, McCarthy, \& LaBar, in press) or by employing ROI-based analytic approaches. Third, the time course of amygdala activity may vary depending on the exact function it serves. In this regard, it is important to distinguish whether amygdala activation reflects emotional reactions or feeling states evoked following recall of an emotional life event, mnemonic processes associated with retrieval attempt/initiation, or emotional evaluation of the recall cue itself (LaBar, 2003). These processes would have different time courses of activation relative to cue onset and may have different sensitivities to control tasks. In the present study, the retrieval cue words themselves were relatively low in emotional impact (see Section 2); therefore, amygdala activation is unlikely due to decoding of the emotional salience of cue itself. Furthermore, the hemodynamic profile of amygdala activation did not have a temporal lag or sustained profile relative to the other regions involved (Fig. 1a). These features suggest that the amygdala is not signaling a resultant feeling state induced following retrieval of the memory. Previous studies that compared fictitious versus non-fictitious emotional events (Markowitsch et al., 2000) or personal versus non-personal traumatic memories (Rausch et al., 1996) have also reported amygdala activation, although its hemispheric distribution has varied. These studies further support an emotional memory function of the amygdala rather than an emotional perception function since the control tasks included presentation of emotionally salient information. These studies, however, used blocked designs that could not temporally distinguish responses at different stages of the retrieval process. Further studies are needed to elucidate which func- tions the amygdala contributes to autobiographical retrieval. ROI-based statistical analyses that do not assume a canonical hemodynamic response profile time-locked to cue onset may be important for disentangling these alternatives.

\subsection{Role of the hippocampus}

Lesion evidence indicates that the hippocampus plays a vital role in episodic memory (Scoville \& Milner, 1957; for reviews, see McClelland et al., 1995; Squire, 1992), and functional neuroimaging evidence shows that this region is activated not only during episodic encoding but also during episodic retrieval (for a review, see Cabeza \& Nyberg, 2000). The role of the hippocampus in the retrieval of remote memories is a matter of dispute (Knowlton \& Fanselow, 1998; Nadel \& Moscovitch, 1997, 1998). Under one view, generally called "consolidation theory," the hippocampus and surrounding areas are required for the encoding of new memories and the retrieval of recent memories, but are not required for the retrieval of remote memories (Alvarez \& Squire, 1994; McClelland et al., 1995; Murre, 1999; Murre, Graham, \& Hodges, 2001; Squire, 1992). The precise definition of "remote" is disputed as well, but patients with bilateral hippocampal damage have retrograde amnesias that last anywhere from months or years to decades. The second view, multiple-trace theory, holds that the hippocampus is always required for the retrieval of episodic memories. Under this view, repeated retrieval of autobiographical memories results in multiple "traces" of the memory within the hippocampal region. For this reason, it is hypothesized that older memories will have more traces distributed throughout the hippocampal region, and will therefore be less susceptible to medial temporal damage (Nadel \& Moscovitch, 1997, 1998, 2001; Nadel, Samsonovich, Ryan, \& Moscovitch, 2000). The present study does not address this issue, as the memories were relatively recent ( 4.8 years old on average; Table 1 ), and both theories would predict hippocampal activation during the retrieval of memories this old.

Recent fMRI evidence suggests some more detailed explanations of our results. One study has shown that the left hippocampus may be more involved in retrieving older memories than the right hemisphere (Maguire \& Frith, 2003). This pattern could explain why hippocampal activations in functional neuroimaging studies of autobiographical memory tend to be left lateralized (Maguire, 2001). Consistent with this trend, in the present study the activation and functional connectivity of the hippocampus during autobiographical memory were left lateralized (Fig. 1); however, the voxel-based analysis did reveal right-sided activation (Table 2) and, as noted previously, the memories were on average less than 5 years old.

Importantly, the activation of the hippocampus during autobiographical memory was greater than the activation of this region during a demanding semantic retrieval task. It is a controversial issue whether episodic and semantic memory, as two forms of declarative memory, are similarly dependent on the hippocampus (e.g. Squire \& Zola, 1998), 
or whether episodic memory is more dependent on the hippocampus than semantic memory (e.g. Aggleton \& Brown, 1999; Mishkin, Vargha-Khadem, \& Gadian, 1998; Tulving \& Markowitsch, 1998; Vargha-Khadem, Gadian, \& Mishkin, 2001). The present results suggest that the hippocampus is involved in both forms of declarative memory, but it plays a greater role in episodic than in semantic memory.

It is important to emphasize that the hippocampus was more activated during autobiographical retrieval than during semantic retrieval, even though the latter was temporally extended. This fact suggests that the difference is not merely related to the amount of information retrieval but the nature of the information retrieved. Recent functional neuroimaging studies of episodic retrieval have associated the hippocampus with the retrieval of specific relational/contextual information, or recollection (e.g. Eldridge et al., 2000; Yonelinas, Hopfinger, Buonocore, Kroll, \& Baynes, 2001). Lesion studies have yielded complementary findings. In episodic memory tasks, people tend to produce more "remember" responses after conceptually-based encoding (Gardiner \& Parkin, 1990). Unilateral temporal lobe epilepsy or excision, however, reduces this effect; for lefthemisphere patients, the effect was eliminated for words, while for right-hemisphere patients, it was eliminated for faces (Moscovitch \& McAndrews, 2002). Thus, both the imaging and the lesion literature show that the hippocampus plays a critical role in the recollection of previously experienced events. Because of the involvement of the self and visuospatial imagery, recollection is likely to play an even greater role in autobiographical than in laboratory episodic memory, and we recently found evidence consistent with this idea using fMRI (Cabeza et al., in press).

\subsection{Role of the IFG}

Markowitsch (1995) has specifically proposed a role for right IFG during retrieval of old episodic memories, given findings of retrograde amnesia following damage to this region and the uncinate fasciculus that connects this region to the anteromedial temporal lobe. Our findings support this idea, especially when considered in combination with the correlational analysis that showed greater functional connectivity among the right IFG, amygdala and hippocampus during autobiographical retrieval. One caveat to this is that activity in the right IFG correlated more strongly with these temporal lobe regions in the left hemisphere (Fig. 3) than in the right hemisphere, where such correlations were found only at a reduced statistical threshold of $p<0.05$ (see Section $3)$. Nonetheless, no temporal lobe regions correlated with the left IFG during autobiographical retrieval (even at a reduced threshold), and the frontotemporal interactions did not generalize to semantic retrieval. These results thus provide some evidence for the strong version of the Markowitsch (1995) hypothesis, although they may indicate frontotemporal interactions during autobiographical retrieval more generally.
In contrast with right IFG, left IFG was more involved in semantic retrieval than in autobiographical retrieval. In particular, the duration of the left IFG activation was longer during semantic than during autobiographical retrieval (Fig. 1c). Even if this difference was partly due to prolonged exemplar generation processes, it challenges the notion that left prefrontal regions play a special role in autobiographical retrieval (Conway et al., 1999; Maguire et al., 2001a,b). For example, Conway et al. (1999) found left prefrontal regions, including IFG, were more activated during the retrieval of autobiographical memories in response to common words (Crovitz technique) than during cued-recall of overlearnt word-pairs. Given that autobiographical trials were short $(4.8 \mathrm{~s})$, the left prefrontal activation could have reflected primarily the generation rather than the monitoring of autobiographical memories. Recent functional neuroimaging evidence suggests that generation processes depend on left prefrontal regions, whereas monitoring processes depend on right prefrontal regions (Cabeza et al., 2003). Thus, the fact that in the present study right IFG played a more important role in autobiographical retrieval than left IFG could be partly a consequence of using participant-specific retrieval cues, which reduced the time required for memory generation and allowed more time for monitoring the retrieval output.

\subsection{Limitations and future directions}

The tasks used in neuroimaging studies of autobiographical memory have varied widely (Maguire, 2001). The prescan cue generation paradigm, which was used here and in several previous studies (Fink et al., 1996; Maguire \& Mummery, 1999; Maguire et al., 2000, 2001; Maguire \& Frith, 2003), has been criticized because it may permit reencoding of the memories. We do not feel that this alternative interpretation explains the greater hippocampal involvement during autobiographical retrieval in our study for three reasons. First, during debriefing, participants in this study reported recalling the memory of the original experience, not the rating session or the previous scanning session, which has also been the case in other studies (Maguire \& Frith, 2003). Second, data from the AMQ showed that participants had often thought or talked about the events, and there is little reason to expect that one additional retrieval would drastically change the memory (see also Piefke et al., 2003). Third, a statistical comparison of the two fMRI testing sessions showed no interaction between session and type of memory retrieval (autobiographical/semantic). One might expect greater hippocampal activation in the autobiographical versus semantic contrast during the first scanning session if such activation reflects the novel association of the event with the cue or if it reflects re-encoding of the event (since by session two, both the autobiographical and semantic memories would be reencoded). On the positive side, this design permits greater control over the time course of retrieval and reduces the number of retrieval failures during the scanning session by using cues that the participants themselves have judged 
to be effective. This design also allowed us to compare the characteristics of participants' memories to those obtained in previous behavioral studies, thereby helping to ensure that participants retrieve full-blown autobiographical memories in the magnet instead of autobiographical facts.

On the other hand, the memory task used in this study did preclude an examination of some relevant questions. Specifically, several earlier studies have compared brain activation in recent and remote memories (Conway et al., 1999; Maguire \& Frith, 2003; Maguire, Henson, Mummery, \& Frith, 2001b; Piefke et al., 2003). In the present study, we used a task that permitted relatively unrestricted generation of autobiographical memories in order to be comparable to the semantic task. An examination of the effects of remoteness would require several additional constraints on memory generation. First, given the distribution of memories across the lifespan (Rubin \& Schulkind, 1997), participants would have to retrieve a certain number of memories from the recent and remote periods (e.g. Piefke et al., 2003). Second, the remote memories would need to be 20-30 years old or older, because neuropsychological (Squire, 1992) and neuroimaging (Maguire \& Frith, 2003) evidence shows that consolidation effects are not necessarily apparent before this time. In this study, however, memories were 4.8 years old on average, and even the oldest memories were no more than 20 years old. Moreover, the levels of detail must be equated to ensure that differences in hippocampal activation cannot be attributed to the greater number of details present in recent memories (Maguire \& Frith, 2003). While our approach did not permit us to address the issue of remoteness, it allowed us to examine a more naturalistic sample of autobiographical memories.

Furthermore, autobiographical retrieval tasks are particularly difficult to control in neuroimaging studies because they can differ in many respects to other retrieval tasks (Maguire, 2001). We chose a prototypical semantic task (category generation) as a control condition to determine whether the activations in the autobiographical retrieval task extended to the domain of semantic retrieval. It is possible that these tasks differed in other cognitive features that account for differential activation in frontotemporal regions. For example, in the autobiographical condition, there is only one correct memory associated with each cue, whereas in the semantic condition, there are multiple correct exemplars associated with each cue. Thus, executive processes related to response selection may have differed across the conditions (although both tasks engaged left IFG). The category generation task was specifically chosen to control for other aspects of autobiographical retrieval, particularly its temporally-extended and iterative nature, which would not have been controlled by other tasks in which semantic processing terminates almost immediately upon cue presentation (e.g. abstract/concrete judgments). In any event, the ROI analyses clearly implicate involvement of the amygdala, hippocampus and IFG during autobiographical retrieval because their time courses were extracted relative to the pre-stimulus baseline without reference to the control task.

Our experimental design consisted of two retrieval sessions. The direct comparison across retrieval sessions did not yield differences in the pattern of brain activation. For this reason, data were combined across testing sessions. Nonetheless, the experience of retrieving in session 1 did have a longlasting impact, since the degree of activation was reduced overall in session 2. Because the activity we report is primarily carried by data obtained from session 1 , a second retrieval session may not be necessary to incorporate in future studies employing similar designs, provided that sufficient power is obtained from one retrieval session.

Due to the targeted nature of our hypotheses, we did not investigate how the frontotemporal regions interacted with other brain regions involved in the network that supports autobiographical memory retrieval (Maguire et al., 2001a,b; Piefke et al., 2003; Ryan et al., 2001), so the pattern of correlations we report here may be extensible to other parts of the brain. The whole-brain SPM analysis did reveal activations in other brain regions that have been reported in previous autobiographical studies, including the precuneus, medial and lateral aspects of the temporal lobe, and the frontal pole. Given the complex, multifactorial nature of autobiographical memory, it will be important to understand the relationship between these regions and other distributed systems important for recollection of people and events from the personal past (Greenberg \& Rubin, 2003; Paller et al., 2003). A remaining challenge is to decompose autobiographical networks into their constituent parts. Parametric studies that vary one or more aspects of autobiographical recollection (e.g. emotional tone or remoteness; Piefke et al., 2003; Maguire \& Frith, 2003) will be critical in this regard. Taking on-line measures of the phenomenological properties of the memories, such as those queried by our autobiographical memory questionnaire, will facilitate these efforts. Finally, as mentioned above, the temporal lag inherent in the autobiographical retrieval process may be exploited in future studies to more carefully map the relationship between activation of different brain regions and their association with different stages of memory retrieval. The results of such studies will have broader implications for biologically-based theories of episodic memory.

\section{Acknowledgements}

This work was supported by the McDonnell Pew Foundation (D.C.R.), a Young Investigator Award from the National Alliance for Research on Schizophrenia and Depression (K.S.L.), National Institutes of Health PHS grants R01 DA14094 (K.S.L.) and R01 AG023123 (D.C.R.), a Ruth L. Kirschstein National Research Service Award (D.L.G.), and the Society for Neuroscience Minority Neuroscience Fellowship Program (H.J.R.). 


\section{Appendix A. Autobiographical memory questionnaire}

Listed below are the questions from our autobiographical memory questionnaire, along with the brief variable name we use for each.

For questions a-g, the scales ranged from 1 (not at all), to 3 (vaguely), to 5 (distinctly), to 7 (as clearly as if it were happening right now).
a. Reliving
As I remember the event, I feel as though I am reliving the original event.
b. Hear
As I remember the event, I can hear it in my mind.
c. See
As I remember the event, I can see it in my mind.
d. Talk
As I remember the event, I or other people are talking.
e. Spatial
As I remember the event, I know its spatial layout.
f. Emotions
As I remember the event, I can feel now the emotional intensity that I felt then.
g. Setting
As I remember the event, I can recall the setting where it occurred.

For questions $\mathrm{h}-\mathrm{n}$, the scales ranged from 1 (not at all), to 3 (vaguely), to 5 (distinctly), to 7 (as much as any memory).
h. Remember/know
Sometimes people know something happened to them without being able to actually remember it. As I think about the event, I can actually remember it rather than just knowing that it happened.
i. In words As I remember the event, it comes to me in words.
j. Back in time
As I remember the event, I feel that I travel back to the time when it happened, that I am a subject in it again, rather than an outside observer tied to the present.
k. Story
As I remember the event, it comes to me in words or in pictures as a coherent story or episode and not as an isolated fact, observation, or scene.
1. Fragmented
My memory of the event is fragmented into specific details with missing bits.
m. General
My memory for the event is only as detailed as the general knowledge of this type of event that I would expect most people to have.
n. Coherence
My memory of the event has a personal coherence: it fits easily into a story I would tell about that part of my life.

The remaining questions had unique scales.

o. Valence

p. Field/observer

q. Real/imagine

r. Rehearsal

s. Once/many
Please rate the emotional valence or the kinds of emotions it involves $(1=100 \%$ negative; $7=100 \%$ positive).

As I remember the event, I imagine it again through my own eyes seeing what I would have seen then, or as an observer from a different perspective than the one I had $(1=$ own eyes; $2=$ observer; $3=$ can't tell).

I believe the event in my memory really occurred in the way I remember it and that I have not imagined or fabricated anything that did not occur (scale: $1=100 \%$ imaginary; $7=100 \%$ real).

Since it happened, I have thought or talked about this event (scale: $1=$ not at all; $7=$ as often as any event in my life).

To the best of your knowledge, is the memory of an event that occurred once at one particular time and place, a summary or merging of many similar or related events, or for events that occurred over a fairly continuous extended period of time lasting more than a day (scale: 1 = once; $2=$ merging; $3=$ extended). 
Responses to this question were recoded to produce two scales. Once/many had a value of 1 if the subject judged the memory to take place within a single day and 0 if it took longer. Merged/extended had a value of 0 if the event lasted longer than a day and was extended in a fairly continuous manner over a period of time and 1 if it was the merging of many discrete events.

t. Age of memory Please date the memory (month/day/year) as accurately as you can. Please fill in a month, day, and year even if you must estimate. If the memory extended over a period of time, report the approximate middle of the period (scored as retention interval in days).

\section{References}

Aggleton, J. P., \& Brown, M. W. (1999). Episodic memory, amnesia, and the hippocampal-anterior thalamic axis. Behavioral and Brain Sciences, 22, 425-489.

Amaral, D. G., Price, J. L., Pitkänen, A., \& Carmichael, S. T. (1992). Anatomical organization of the primate amygdaloid complex. In J. P. Aggleton (Ed.), The amygdala: Neurobiological aspects of emotion, memory, and mental dysfunction (pp. 1-66). New York: Wiley-Liss.

Andreasen, N. C., O’Leary, D. S., Cizadlo, T., Arndt, S., Rezai, K., Watkins, G. L., et al. (1995). Remembering the past: two facets of episodic memory explored with positron emission tomography. American Journal of Psychiatry, 11, 1576-1585.

Baddeley, A. D. (1992). What is autobiographical memory? In M. A. Conway, D. C. Rubin, H. Spinnler, \& W. A. Wagenaar (Eds.), Theoretical perspectives on autobiographical memory (pp. 13-29). Dordrecht, The Netherlands: Kluwer Academic Publishers.

Baddeley, A., \& Wilson, B. (1986). Amnesia, autobiographical memory, and confabulation. In D. C. Rubin (Ed.), Autobiographical memory (pp. 225-252). New York: Cambridge University Press.

Bahrick, H. P. (1979). Maintenance of knowledge: Questions about memory we forgot to ask. Journal of Experimental Psychology: General, 108, 296-308.

Battig, W. F., \& Montague, W. E. (1969). Category norms for verbal items in 56 categories: A replication and extension of the Connecticut category norms. Journal of Experimental Psychology, 80, 145.

Bluck, S., \& Li, K. Z. H. (2001). Predicting memory completeness and accuracy: Emotion and exposure in repeated autobiographical recall. Applied Cognitive Psychology, 15, 145-158.

Breiter, H. C., Etcoff, N. L., Whalen, P. J., Kennedy, W. A., Rauch, S. L., Buckner, R. L., et al. (1996). Response and habituation of the human amygdala during visual processing of facial expression. Neuron, 17, $875-887$.

Brewer, W. F. (1986). What is autobiographical memory? In D. C. Rubin (Ed.), Autobiographical memory (pp. 25-49). New York: Cambridge University Press.

Brewer, W. F. (1995). What is recollective memory? In D. C. Rubin (Ed.), Remembering our past: Studies in autobiographical memory (pp. 19-66).

Cabeza, R., Kester Locantore, J., \& Anderson, N. D. (2003). Lateralization of prefrontal cortex activity during episodic memory retrieval: Evidence for the production-monitoring hypothesis. Journal of Cognitive Neuroscience, 15, 249-259.

Cabeza, R., \& Nyberg, L. (2000). Imaging cognition II: An empirical review of 275 PET and fMRI studies. Journal of Cognitive Neuroscience, 12, 1-47.

Cabeza, R., Prince, S. E., Daselaar, S. M., Greenberg, D., Budde, M., Dolcos, F., et al. Brain activity during episodic retrieval of autobiographical and laboratory events: An fMRI study using a novel photo paradigm. Journal of Cognitive Neuroscience (in press).

Cahill, L., \& McGaugh, J. L. (1998). Mechanisms of emotional arousal and lasting declarative memory. Trends in Neurosciences, 21, 294-299.

Calabrese, P., Markowitsch, H. J., Durwen, H. F., Widlitzek, H., Haupts, M., Holinka, B., et al. (1996). Right temporofrontal cortex as critical locus for the ecphory of old episodic memories. Journal of Neurology, Neurosurgery \& Psychiatry, 61, 304-310.

Christianson, S. -Å. (1992). The handbook of emotion and memory: Research and theory. Hillsdale, NJ: Lawrence Erlbaum Associates.

Christianson, S. - ̊., \& Safer, M. (1995). Emotional events and emotions in autobiographical memories. In D. C. Rubin (Ed.), Remembering our past: Studies in autobiographical memory (pp. 218-243). New York: Cambridge University Press.

Conway, M. A., Pleydell-Pearce, C. W., Whitecross, S. E., \& Sharpe, H. (2003). Neurophysiological correlates of memory for experienced and imagined events. Neuropsychologia, 41, 334-340.

Conway, M. A., Pleydell-Pearce, C. W., \& Whitecross, S. E. (2001). The neuroanatomy of autobiographical memory: A slow cortical potential study of autobiographical memory retrieval. Journal of Memory and Language, 45, 493-524.

Conway, M. A., Turk, D. J., Miller, S. L., Logan, J., Nebes, R. D., Meltzer, C. C., et al. (1999). A positron emission tomography (PET) study of autobiographical memory retrieval. Memory, 7, 679-702.

Convit, A., McHugh, P., Wolf, O. T., de Leon, M. J., Bobinski, M., \& De Santi, S. (1999). MRI volume of the amygdala: A reliable method allowing separation from the hippocampal formation. Psychiatry Research: Neuroimaging Section, 90, 113-123.

Crovitz, H. F. (1986). Loss and recovery of autobiographical memory after head injury. In D. C. Rubin (Ed.), Autobiographical memory (pp. 273-290). New York: Cambridge University Press.

Crovitz, H. F., \& Schiffman, H. (1974). Frequency of episodic memories as a function of their age. Bulletin of the Psychonomic Society, 4, 517-518.

Damasio, A. R., Grabowski, T. J., Bechara, A., Damasio, H., Ponto, L. L. B., Parvisi, J., et al. (2000). Subcortical and cortical brain activity during the feeling of self-generated emotions. Nature Neuroscience, 3, 1049-1056.

Dolan, R. J., Lane, R., Chua, P., \& Fletcher, P. (2000). Dissociable temporal lobe activations during emotional episodic memory retrieval. NeuroImage, 11, 203-209.

Dolcos, F., LaBar, K. S., \& Cabeza, R. (2004). Interactions between the amygdala and the medial temporal lobe memory system predict better memory for emotional events. Neuron, 42, 855-863.

Duvernoy, H. M. (1999). The human brain: Surface, blood supply, and three-dimensional sectional anatomy. New York: Springer-Verlag.

Eldridge, L. L., Knowlton, B. J., Furmanski, C. S., Bookheimer, S. Y., \& Engle, S. A. (2000). Remembering episodes: A selective role for the hippocampus during retrieval. Nature Neuroscience, 3, 11491152.

Fink, G., Markowitsch, H. J., Reinkemeier, M., Bruckbauer, T., Kessler, J., \& Heiss, W. -D. (1996). Cerebral representation of one's own past: Neural networks involved in autobiographical memory. Journal of Neuroscience, 16, 4275-4282.

Gardiner, J. M., \& Parkin, A. J. (1990). Attention and recollective experience in recognition memory. Memory \& Cognition, 18, 579-583.

George, M. S., Ketter, T. A., Parekh, P. I., Herscovitch, P., \& Post, R. M. (1996). Gender differences in regional cerebral blood flow during transient self-induced sadness or happiness. Biological Psychiatry, 40, $859-871$.

George, M. S., Ketter, T. A., Parekh, P. I., Horwitz, B., Herscovitch, P., \& Post, R. M. (1995). Brain activity during transient sadness and 
happiness in healthy women. American Journal of Psychiatry, 152, 341-351.

Greenberg, D. L., \& Rubin, D. C. (2003). The neuropsychology of autobiographical memory. Cortex, 39, 687-728.

Hamann, S. B. (2001). Cognitive and neural mechanisms of emotional memory. Trends in Cognitive Sciences, 9, 394-400.

Hamann, S. B., Elt, T., Grafton, S., \& Kilts, C. (1999). Amygdala activity related to enhanced memory for pleasant and aversive stimuli. Nature Neuroscience, 2, 289-293.

Knowlton, B. J., \& Fanselow, M. S. (1998). The hippocampus, consolidation and on-line memory. Current Opinion in Neurobiology, 8, 293-296.

Kroll, N. E. A., Markowitsch, H. J., Knight, R. T., \& von Cramon, D. Y. (1997). Retrieval of old memories: The temporofrontal hypothesis. Brain, 120, 1377-1399.

LaBar, K. S. (2003). Emotional memory functions of the human amygdala. Current Neurology and Neuroscience Reports, 3, 363-364.

LaBar, K. S., Gitelman, D. R., Mesulam, M. -M., \& Parrish, T. B. (2001). Impact of signal-to-noise on functional MRI of the human amygdala. Neuroreport, 12, 3461-3464.

Lane, R. D., Reiman, E. M., Bradley, M. M., Lang, P. J., Ahern, G. L., Davidson, R. J., et al. (1997). Neuroanatomical correlates of pleasant and unpleasant emotion. Neuropsychologia, 35, 1437-1444.

Larsen, S. (1998). What is it like to remember? On phenomenal qualities of memory. In C. P. Thompson, D. J. Herrmann, D. Bruce, J. D. Read, D. G. Payne, \& M. P. Toglia (Eds.), Autobiographical memory: Theoretical and applied perspectives (pp. 163-190). Mahwah, NJ: Erlbaum.

Lepage, M., Habib, R., \& Tulving, E. (1998). Hippocampal PET activations of memory encoding and retrieval: The HIPER model. Hippocampus, 8, 313-322.

Levine, B., Black, S. E., Cabeza, R., Sinden, M., McIntosh, A. R., Toth, J. P., et al. (1998). Episodic memory and the self in a case of isolated retrograde amnesia. Brain, 121, 1951-1973.

Liotti, M., Mayberg, H. S., Brannan, S. K., McGinnis, S., Jerabek, P., \& Fox, P. T. (2000). Differential limbic-cortical correlates of sadness and anxiety in healthy subjects: Implications for affective disorders. Biological Psychiatry, 48, 30-42.

Maguire, E. A. (2001). Neuroimaging studies of autobiographical event memory. Philosophical Transactions of the Royal Society of London B: Biological Sciences, 356, 1441-1451.

Maguire, E. A., \& Frith, C. D. (2003). Lateral asymmetry in the hippocampal response to the remoteness of autobiographical memories. Journal of Neuroscience, 23, 5302-5307.

Maguire, E. A., Henson, R. N. A., Mummery, C. J., \& Frith, C. D. (2001). Activity in prefrontal cortex, not hippocampus, varies parametrically with the increasing remoteness of memory. Neuroreport, 124, 1156-1170.

Maguire, E. A., \& Mummery, C. J. (1999). Differential modulation of a common memory retrieval network revealed by positron emission tomography. Hippocampus, 9, 54-61.

Maguire, E. A., Mummery, C. J., \& Büchel, C. (2000). Patterns of hippocampal-cortical interaction dissociate temporal lobe memory systems. Hippocampus, 10, 475-482.

Maguire, E. A., Vargha-Khadem, F., \& Mishkin, M. (2001). The effects of bilateral hippocampal damage on fMRI regional activations and interactions during memory retrieval. Brain, 124, 1156-1170.

Markowitsch, H. J. (1995). Which brain regions are critically involved in the retrieval of old episodic memory? Brain Research Reviews, 21, $117-127$.

Markowitsch, H. J., Thiel, A., Reinkemeier, M., Kessler, J., Koyuncu, A., \& Heiss, W. -D. (2000). Right amygdalar and temporofrontal activation during autobiographic, but not during fictitious memory retrieval. Behavioral Neurology, 12, 181-190.

Mayberg, H. S., Liotti, M., Brannan, S. K., McGinnis, S., Mahurin, R. K., Jerabek, P. A., et al. (1999). Reciprocal limbic-cortical function and negative mood: Converging PET findings in depression and normal sadness. American Journal of Psychiatry, 156, 675682.

McClelland, J., McNaughton, B., \& O'Reilly, R. (1995). Why there are complementary learning systems in the hippocampus and neocortex: Insights from the successes and failures of connectionist models of learning and memory. Psychological Review, 102, 419-457.

McNally, R. J., Litz, B. T., Prassas, A., Shin, L. M., \& Weathers, F. W. (1994). Emotional priming of autobiographical memory in posttraumatic stress disorder. Cognition \& Emotion, 8, 351-367.

Mishkin, M., Vargha-Khadem, F., \& Gadian, D. G. (1998). Amnesia and the organization of the hippocampal system. Hippocampus, 8 , 212-216.

Mori, E., Ikeda, M., Hirono, N., Kitagaki, H., Imamura, T., \& Shimomura, T. (1999). Amygdalar volume and emotional memory in Alzheimer's disease. American Journal of Psychiatry, 156, 216-222.

Moscovitch, D. A., \& McAndrews, M. P. (2002). Material-specific deficits in "remembering" in patients with unilateral temporal lobe epilepsy and excisions. Neuropsychologia, 40, 1335-1342.

Moscovitch, M. (1989). Confabulation and the frontal systems. In H. L. Roediger \& F. I. M. Craik (Eds.), Varieties of memory and consciousness: Essays in honour of Endel Tulving (pp. 133-160). Hillsdale, NJ: Lawrence Erlbaum Associates.

Moscovitch, M., \& Melo, B. (1997). Strategic retrieval and the frontal lobes: Evidence from confabulation and amnesia. Neuropsychologia, 35, 1017-1034.

Murre, J. M. J., Graham, K. S., \& Hodges, J. R. (2001). Semantic dementia: Relevance to connectionist models of long-term memory. Brain, 124, 647-675.

Nadel, L., \& Moscovitch, M. (1997). Memory consolidation, retrograde amnesia, and the hippocampal complex. Current Opinion in Neurobiology, 7, 217-227.

Nadel, L., \& Moscovitch, M. (1998). Hippocampal contributions to cortical plasticity. Neuropharmacology, 37, 431-439.

Nadel, L., \& Moscovitch, M. (2001). The hippocampal complex and longterm memory revisited. Trends in Cognitive Sciences, 5, 228-230.

Nadel, L., Samsonovich, A., Ryan, L., \& Moscovitch, M. (2000). Multiple trace theory of human memory: Computational, neuroimaging, and neuropsychological results. Hippocampus, 10, 352-368.

Nigro, G., \& Neisser, U. (1983). Point of view in personal memories. Cognitive Psychology, 15, 467-482.

O'Connor, M., Butters, N., Miliotis, P., Eslinger, P., \& Cermak, L. S. (1992). The dissociation of anterograde and retrograde amnesia in a patient with herpes simplex encephalitis. Journal of Clinical and Experimental Neuropsychology, 14, 159-178.

Paller, K. A., Ranganath, C., Gonsalves, B., LaBar, K. S., Parrish, T. B., Gitelman, D. R., et al. (2003). Neural correlates of person recognition. Learning \& Memory, 10, 253-260.

Pardo, J. V., Pardo, P. J., \& Raichle, M. E. (1993). Neural correlates of self-induced dysphoria. American Journal of Psychiatry, 150, 713-719.

Piefke, M., Weiss, P. H., Zilles, K., Markowitsch, H. J., \& Fink, G. (2003). Differential remoteness and emotional tone modulate the neural correlates of autobiographical memory. Brain, 126, 650668.

Posse, S., Fitzgerald, D., Gao, K., Habel, U., Rosenberg, D., Moore, G. J., et al. (2003). Real-time fMRI of temporolimbic regions detects amygdala activation during single-trial self-induced sadness. NeuroImage, 18, 760-768.

Rausch, S. L., van der Kolk, B. A., Fisler, R. E., Alpert, N. M., Orr, S. P., Savage, C. R., et al. (1996). A symptom provocation study of posttraumatic stress disorder using positron emission tomography and script-driven imagery. Archives of General Psychiatry, 53, 380-387.

Reisberg, D. (1992). Auditory imagery. Hillsdale, NJ: Lawrence Erlbaum Associates.

Reisberg, D., Heuer, F., MacLean, J., \& O'Shaughnessy, M. (1988). The quantity, not the quality, of affect predicts memory vividness. Bulletin of the Psychonomic Society, 26, 100-103. 
Rubin, D. C. (1995). Memory in oral traditions: The cognitive psychology of epic, ballads, and counting-out rhymes. New York: Oxford University Press.

Rubin, D. C. (1998). Beginnings of a theory of autobiographical remembering. In C. P. Thompson, D. J. Hermann, D. Bruce, J. D. Reed, D. G. Payne, \& M. P. Toglia (Eds.), Autobiographical memory: Theoretical and applied perspectives (pp. 47-67). Mahwah, NJ: Erlbaum.

Rubin, D. C., \& Greenberg, D. L. (1998). Visual memory-deficit amnesia: A distinct amnesic presentation and etiology. Proceedings of the National Academy of Sciences of the United States of America, 95, 5413-5416.

Rubin, D. C., \& Greenberg, D. L. (2003). The role of narrative in recollection: a view from cognitive and neuropsychology. In G. Fireman, T. McVay, \& O. Flanagan (Eds.), Narrative and consciousness: Literature, psychology, and the brain. New York: Oxford University Press.

Rubin, D. C., Groth, E., \& Goldsmith, D. J. (1984). Olfactory cuing of autobiographical memory. American Journal of Psychology, 97, 493-507.

Rubin, D. C., Schrauf, R. W., \& Greenberg, D. L. (2003). Belief and recollection of autobiographical memories. Memory \& Cognition, 31, 887-901.

Rubin, D. C., \& Schulkind, M. D. (1997). Distribution of important and word-cued autobiographical memories in 20-, 35-, and 70-year-old adults. Psychology and Aging, 12, 524-535.

Ryan, L., Nadel, L., Keil, K., Putnam, K., Schnyer, D., Trouard, T., et al. (2001). Hippocampal complex and retrieval of recent and very remote autobiographical memories: Evidence from functional magnetic resonance imaging in neurologically intact people. Hippocampus, 11, 707-714.

Schacter, D. L., Norman, K. A., \& Koutstaal, W. (1998). The cognitive neuroscience of constructive memory. Annual Review of Psychology, 49, 289-318.

Schacter, D. L., \& Wagner, A. D. (1999). Medial temporal lobe activations in fMRI and PET studies of episodic encoding and retrieval. Hippocampus, 8, 7-24.

Schrauf, R. W., \& Rubin, D. C. (1998). Bilingual autobiographical memory in older adult immigrants: A test of cognitive explanations of the reminiscence bump and the linguistic encoding of memories. Journal of Memory \& Language, 39, 437-457.

Scoville, W. B., \& Milner, B. (1957). Loss of recent memory after bilateral hippocampal lesions. Journal of Neurology, Neurosurgery \& Psychiatry, 20, 11-21.

Squire, L. R. (1992). Memory and the hippocampus: A synthesis from findings with rats, monkeys, and humans. Psychological Review, 99, 195-231.

Squire, L. R., \& Zola, S. (1998). Episodic memory, semantic memory, and amnesia. Hippocampus, 8, 205-211.

Strange, B. A., Fletcher, P. C., Henson, R. N. A., Friston, K. J., \& Dolan, R. J. (1999). Segregating the functions of human hippocampus. Proceedings of the National Academy of Sciences of the United States of America, 96, 4034-4039.

Talairach, J., \& Tournoux, P. (1988). Co-planar stereotaxic atlas of the human brain. New York: Thieme.

Talarico, J., LaBar, K. S., \& Rubin, D. C. Emotional intensity predicts autobiographical memory experience (in press).
Talland, G. A. (1965). Deranged memory. New York: Academic Press. Taylor, S. F., Liberzon, I., Fig, L. M., Decker, L. R., Minoshima, S., \& Koeppe, R. A. (1998). The effect of emotional content on visual recognition memory: A PET activation study. NeuroImage, 8 , 188-197.

Thompson-Schill, S. L. (2003). Neuroimaging studies of semantic memory: Inferring "how" from "where". Neuropsychologia, 41, 280292.

Tulving, E. (1972). Episodic and semantic memory. In E. Tulving \& W. Donaldson (Eds.), Organisation of memory (pp. 381-403). New York: Academic Press.

Tulving, E. (1983). Elements of episodic memory. New York: Oxford University Press.

Tulving, E. (1985). Memory and consciousness. Canadian Psychology, 26, 1-12.

Tulving, E., \& Markowitsch, H. J. (1998). Episodic and declarative memory: Role of the hippocampus. Hippocampus, 8, 198-204.

Ungerleider, L. M., \& Mishkin, M. (1982). Two cortical visual systems. In D. J. Ingle, M. A. Goodale, \& R. J. W. Mansfield (Eds.), Analysis of visual behavior (pp. 549-586). Cambridge, MA: MIT Press.

Vargha-Khadem, F., Gadian, D. G., \& Mishkin, M. (2001). Dissociations in cognitive memory: The syndrome of developmental amnesia. Philosophical Transactions of the Royal Society of London Series B: Biological Sciences of the United States of America, 356, 14351440.

Velanova, K., Jacoby, L. L., Wheeler, M. E., McAvoy, M. P., Petersen, S. E., \& Buckner, R. L. (2003). Functional-anatomic correlates of sustained and transient processing components engaged during controlled retrieval. Journal of Neuroscience, 23, 8460-8470.

Voyvodic, J. T. (1999). Real-time fMRI paradigm control, physiology, and behavior combined with near real-time statistical analysis. NeuroImage, 10, 91-106.

Wagner, A. D., Desmond, J. E., Glover, G., \& Gabrieli, J. D. E. (1998). Prefrontal cortex and recognition memory: Functional-MRI evidence for context-dependent retrieval processes. Brain, 121, 1985-2002.

Wagner, A. D., Maril, A., Bjork, R. A., \& Schacter, D. L. (2001). Prefrontal contributions to executive control: fMRI evidence for functional distinctions within lateral prefrontal cortex. NeuroImage, 14, 1337-1347.

Wang, L., Song, A. W., McCarthy, G., \& LaBar, K. S. Amygdala activation to sad pictures during high-field (4 Tesla) functional magnetic resonance imaging. Emotion (in press).

Wheeler, M. A., Stuss, D. T., \& Tulving, E. (1997). Toward a theory of episodic memory: The frontal lobes and autonoetic consciousness. Psychological Bulletin, 121, 331-354.

Williams, J. M. G. (1995). Depression and the specificity of autobiographical memory. In D. C. Rubin (Ed.), Remembering our past: Studies in autobiographical memory (pp. 244-270). New York: Cambridge University Press.

Yamasaki, H., LaBar, K. S., \& McCarthy, G. (2002). Dissociable prefrontal brain systems for attention and emotion.

Yonelinas, A. P., Hopfinger, J. B., Buonocore, M. H., Kroll, N. E. A., \& Baynes, K. (2001). Hippocampal, parahippocampal and occipitaltemporal contributions to associative and item recognition memory: An fMRI study. Neuroreport, 12, 359-363. 